\title{
Abscisic acid (ABA) enhances beta cell function under glucolipotoxicity conditions
}

\author{
Fadi Alkayal, Hossein Arefanian, Eman Al Shawaf, Sulaiman Marafie, Ali Tiss \\ Research Division, Dasman Diabetes Institute, Kuwait
}

\section{Overview}

Background: In type 2 diabetes, hyperglycemia in combination with high levels of free fatty acids, a condition known as glucolipotoxicity, affects the mass viability and function of beta cells. In plants, the phyto-hormone abscisic acid (ABA) prevents cell apoptosis and DNA degradation ${ }^{1}$ whereas $A B A$ in humans reportedly induces insulin secretion ${ }^{2}$, reduces insulin resistance ${ }^{3}$, lowers fasting blood glucose and improves glucose tolerance ${ }^{4}$. Objectives: Here, we hypothesized that ABA might have similar protective effects in mammalian beta cells under glucolipotoxic conditions. Thus, we have investigated the effects of $A B A$ on the viability and function o mammalian beta cells treated with high levels of glucose and palmitic acid (PA).

Results: The abundance of key proteins involved in insulin signaling was modulated by $A B A$ in the presence of high levels of glucose and PA. The expression of the transcription factors PDX1, RICTOR, and MAP4K4 was increased under treatment with $A B A$, while the expression of pathways downstream of ANGPT2 and of pirinixic acid was inhibited under these conditions. Interestingly, canonical signaling pathways such as those involving EIF2, PKA, and the NRF2-mediated Oxidative Stress Response were also clearly modulated by ABA.

\section{Material \& Methods}

\section{Cell culture and treatment:}

The rat insulinoma INS-1 832/13 cells were cultured in RPMI-1640 medium supplemented with $10 \%$ fetal bovine serum, $100 \mathrm{U} / \mathrm{mL}$ penicillin and $100 \mu \mathrm{g} / \mathrm{mL}$ streptomycin, $1 \mathrm{mM}$ Sodium pyruvate, $10 \mathrm{mM}$ HEPES and $0.05 \mathrm{mM} 2$ Mercabtoethanol at $37^{\circ} \mathrm{C}$ in a humidified atmosphere containing $95 \%$ air and $5 \%$ $\mathrm{CO}_{2}$. When reached confluence, INS-1 cells were washed with PBS pH 7.2, treated with $0.05 \%$ trypsin for 4 min then suspended in fresh media. $2.5 \times 10^{5}$ cells were seeded in $10 \mathrm{~mm}$ dishes supplied with normal media (11.1 mM glucose) for $48 \mathrm{hr}$ for adhering then incubated in modified medium with and without (10nM ABA) under the following conditions:

$$
\begin{aligned}
& >16.7 \mathrm{mM} \text { Glucose. } \\
& >400 \mu \mathrm{M} \text { Palmitic acid. } \\
& >16.7 \mathrm{mM} \text { Glucose and } 400 \mu \mathrm{M} \text { PA (Glucolipotoxicity). }
\end{aligned}
$$

PA was conjugated to bovine serum albumin FFA-free (BSA) (Millipore) at a 2:1 molar ratio. Control cells were incubated with media containing FFA-free BSA at the same concentration as exposed cells. Cells were maintained for 14 days with refreshing the media on days 4,8 , and 12 and finally harvested for protein extractions.

Cell viability using MTT assay:

Cell viability experiments were conducted in 24 -well plates $\left(1.0 \times 10^{4}\right.$ were seeded per well) using TACS MTT assay (Trevigen, Inc.).

Protein extraction and digestion for proteomics analysis:

Proteins were extracted from cells, fractionated and digested on SCX beads and then analyzed by LC- Orbitrap Velos platform and label-free quantified. Briefly, 3 independent repeats of cell cultures were pelleted and lysed in $200 \mu \mathrm{L}$ of buffer ( $2 \mathrm{M}$ urea, $4 \%$ CHAPS) with a mini-complete protease inhibitor cocktail for $30 \mathrm{~min}$ at $4^{\circ} \mathrm{C}$. $20 \mu \mathrm{g}$ of proteins were added to $10 \mu \mathrm{L}$ of strong cationic exchange (BcMag ${ }^{\mathrm{TM}}$ SCX Magnetic bead slurry, Bioclone) in $1 \mathrm{ml}$ of $5 \%$ formic acid, centrifuged at $10,000 \times \mathrm{xg}$, the pellet was resuspended in $1 \mathrm{ml}$ of $0.5 \%$ formic acid and then, reduced with $20 \mathrm{mM}$ DTT and then alkylated with $100 \mathrm{mM}$ iodoacetamide. The alkylation reaction was stopped by adding $1 \mathrm{ml}$ of $0.5 \%$ formic acid. The beads were centrifuged and proteins were digested with Trypsin overnight at $37^{\circ} \mathrm{C}$ and then, eluted with $300 \mu \mathrm{L}$ of Ammonia (pH 12)

\section{NanoLC-MS/MS Analysis:}

Peptide digest analysis was done using an Easy nano-LC (C18-A1 pre-column, and C18-A2 analytical column) coupled to an LTQ-Orbitrap Velos. Peptides were eluted with a gradient of 5 to $35 \%$ acetonitrile with $0.1 \%$ formic acid over $80 \mathrm{~min}$. Full MS spectra scan was performed at a resolution of $60,000 . \mathrm{MS} / \mathrm{MS}$ spectra were acquired in a DDA mode. Data were analyzed using Sequest and Mascot search engines. MaxQuant software was used for quantification of identified proteins and IPA software for pathways analysis

\section{References:}

Contact information :
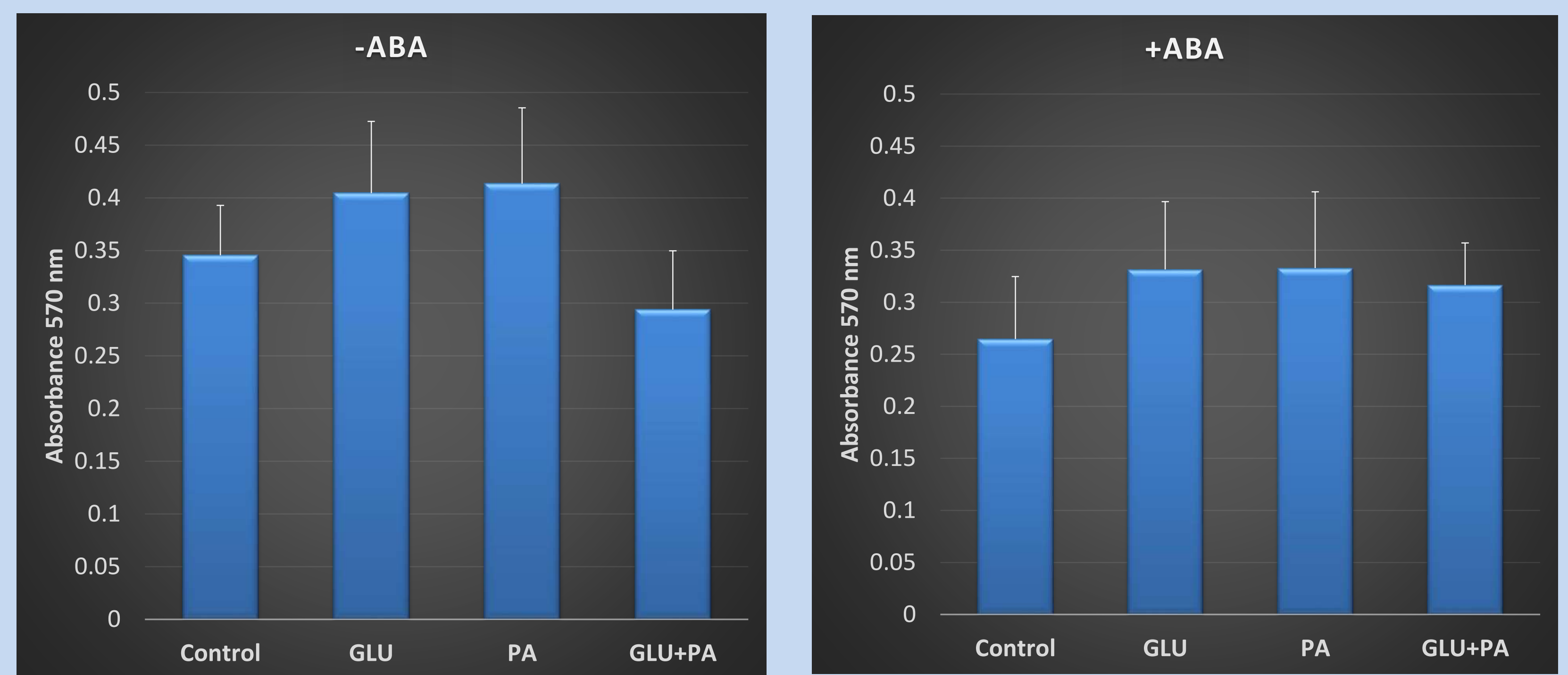

Figure 1: The influence of various treatment conditions on INS-1 cells growth w/wo 10nM ABA

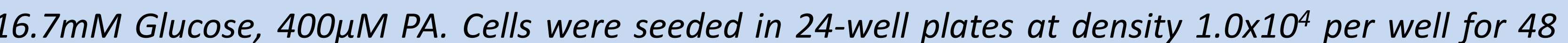
hours in normal medium to adhere then subjected to treatment conditions for 14 days.

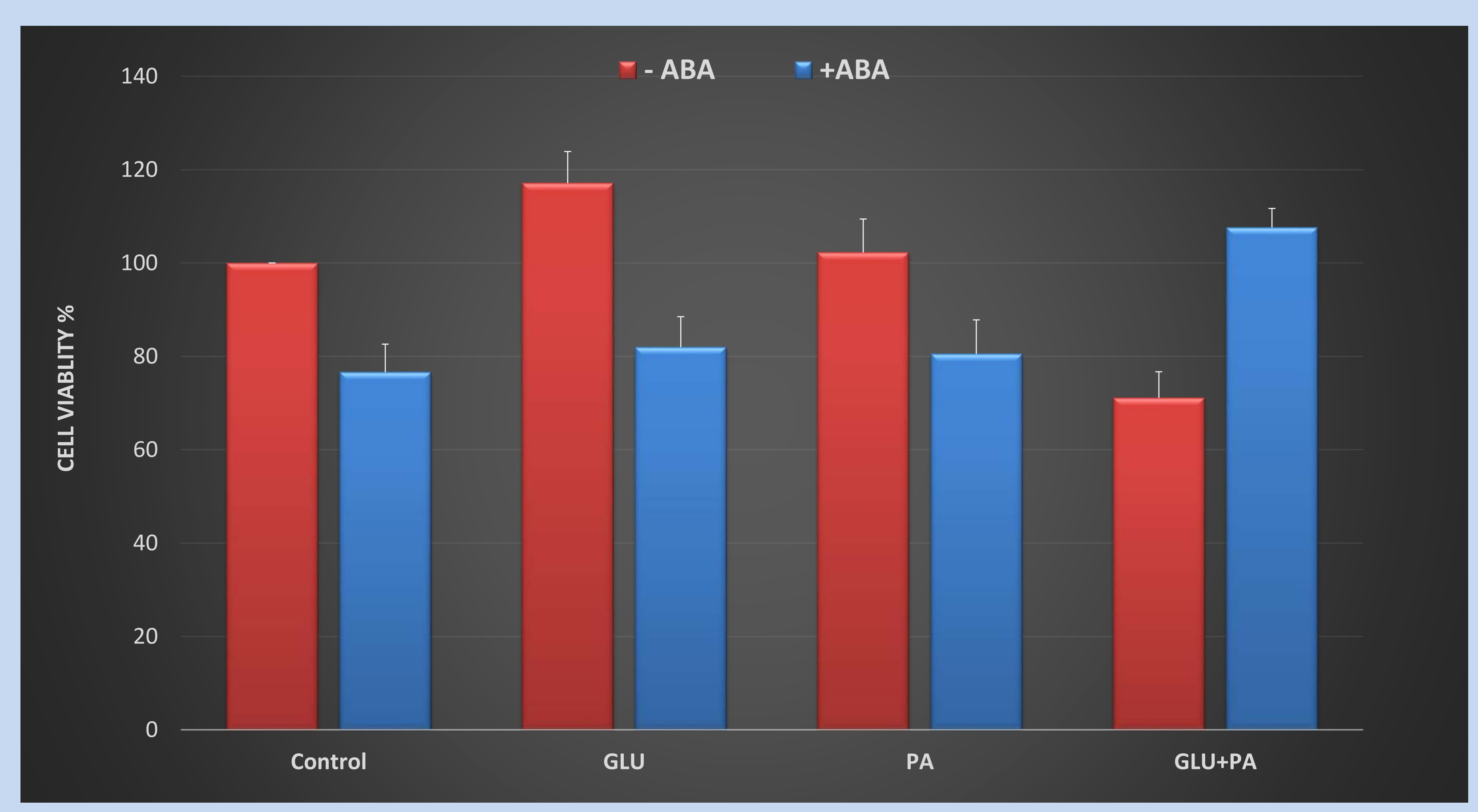

Figure 2:. Effect of ABA on INS-1 proliferation. Cells were cultured in up normal conditions in the

\begin{tabular}{|c|c|c|c|c|c|c|c|c|}
\hline \multirow{2}{*}{$\begin{array}{l}\text { Altered } \\
\text { Regulator }\end{array}$} & \multicolumn{2}{|c|}{ Control } & \multicolumn{2}{|c|}{ Glu } & \multicolumn{2}{|c|}{ PA } & \multicolumn{2}{|c|}{ Glu+PA } \\
\hline & z-score & p-value & z-score & p-value & z-score & p-value & z-score & $p$-value \\
\hline ANGPT2 & -1.914 & 0.0391 & NS & & -1.287 & 0.000235 & NS & \\
\hline ATF4 & -2.401 & 0.0402 & -1.484 & 0.0393 & NS & & NS & \\
\hline CNR1 & -1.633 & 0.0314 & -1.342 & 0.0291 & NS & & NS & \\
\hline CREB1 & -2.206 & 0.00219 & NS & & -1.091 & 0.0158 & NS & \\
\hline CST5 & 1.213 & 0.00000271 & NS & & NS & & 2.121 & 0.0108 \\
\hline E2f & NS & & -1.972 & 0.0179 & NS & & NS & \\
\hline E2F1 & -1.135 & $8.46 \mathrm{E}-09$ & -2.178 & 0.000721 & NS & & 1.914 & 0.00202 \\
\hline Foxo1 & -2.598 & 0.0289 & NS & & NS & & NS & \\
\hline GATA6 & 2.236 & 0.151 & & & NS & & -1.6 & 0.0118 \\
\hline Ins1 & -1.988 & 0.0215 & -1.432 & 0.0299 & -1.105 & 0.00223 & NS & \\
\hline INSR & -2.622 & $3.08 \mathrm{E}-10$ & 1.234 & 0.00818 & NS & & 1.561 & 0.000151 \\
\hline Insulin & -1.886 & 0.118 & & & NS & & NS & \\
\hline IRF4 & 1.414 & 0.00261 & 1.342 & 0.0323 & NS & & 1 & 0.0209 \\
\hline KLF15 & -2.232 & 0.000743 & -1.616 & 0.0000146 & NS & & NS & \\
\hline KLF3 & NS & & NS & & NS & & 1.387 & 0.0000782 \\
\hline KLF5 & -1.131 & 0.0117 & NS & & NS & & NS & \\
\hline MAP4K4 & 3.148 & 0.0000154 & 1.066 & 0.0000107 & NS & & -2.121 & 0.000034 \\
\hline MEL T1 & 1.342 & 0.00000389 & -2 & 0.0000346 & NS & & NS & \\
\hline MYCN & -1.961 & 0.000571 & 2 & 0.0185 & NS & & NS & \\
\hline NFE2L1 & -2 & 0.00206 & NS & & NS & & NS & \\
\hline NFE2L2 & -4.69 & 3.57E-09 & NS & & NS & & NS & \\
\hline NFKBIA & NS & & NS & & -1.213 & 0.0461 & NS & \\
\hline NRF1 & -1.114 & 0.001 & NS & & NS & & NS & \\
\hline NUPR1 & 2.449 & & 2.121 & 0.273 & NS & & NS & \\
\hline PDX1 & 2.121 & 0.000000125 & NS & & 1.091 & 0.0412 & NS & \\
\hline PGR & -2.897 & 0.000552 & -1.622 & 0.0067 & NS & & NS & \\
\hline PML & 1.4 & 0.0161 & 1.414 & 0.00000308 & NS & & NS & \\
\hline PPARG & -1.991 & 0.147 & -1.748 & 0.00417 & 1.281 & 0.0000397 & NS & \\
\hline PTEN & -1.051 & 0.00364 & NS & & -1.7 & 0.0223 & NS & \\
\hline RBL1 & 1 & 0.00129 & 1.725 & 0.00026 & NS & & -1.929 & 0.00309 \\
\hline RBL2 & 1.961 & 0.0234 & NS & & NS & & NS & \\
\hline RICTOR & 3.68 & $4.81 E-18$ & 1.06 & $1.96 E-17$ & NS & & NS & \\
\hline SP1 & NS & & -1.19 & 0.00303 & NS & & -1.982 & 0.0476 \\
\hline SPP1 & NS & & NS & & 1.732 & 0.0429 & 1.941 & 0.463 \\
\hline SREBF1 & -1.774 & 0.00721 & -1.44 & 0.00309 & NS & & 2 & 0.189 \\
\hline SREBF2 & -2.366 & 0.00129 & -1.284 & 0.000262 & NS & & -2.236 & 0.0163 \\
\hline TCF3 & 1.982 & 0.481 & & & NS & & NS & \\
\hline TGFB1 & NS & & -1.795 & 0.000959 & NS & & NS & \\
\hline TFEB & -1.997 & 0.00377 & NS & & -1.154 & 0.000801 & NS & \\
\hline TP53 & NS & & 1.996 & 0.00000242 & & & NS & \\
\hline TP63 & -2.588 & 0.0424 & NS & & NS & & NS & \\
\hline TRAP1 & 2.236 & 0.000195 & -1.463 & 0.00000395 & NS & & NS & \\
\hline TSC2 & 1.069 & 0.0098 & -1.067 & 0.0479 & NS & & NS & \\
\hline UCP1 & -1.572 & 0.00585 & 1 & 0.0262 & NS & & NS & \\
\hline VEGFA & -2.557 & 0.0137 & -1.154 & 0.00517 & NS & & NS & \\
\hline XBP1 & -1.558 & 0.00000137 & NS & & NS & & -1.011 & 0.000395 \\
\hline
\end{tabular}
presence or absence of $16.7 \mathrm{mM}$ glucose, 400uM PA, 10nM ABA for 14 days (to reach $80 \%$ confluence in control plate).

\section{Conclusion}

Specific pathways and proteins modulated by $A B A$ and identified in the present study provide insight into the potential beneficial effects of $A B A$ in protecting beta cells against glucolipotoxic conditions and might promote the use of $A B A$ in the prevention and management of diabetes. 